\title{
Brief report: ethical problems in research practice
}

\author{
Gunnel Colnerud
}

\section{Linköping University Post Print}

\section{Tweet}

N.B.: When citing this work, cite the original article.

Original Publication:

Gunnel Colnerud, Brief report: ethical problems in research practice, 2013, Journal of Empirical Research on Human Research Ethics, (8), 4, 37-41.

http://dx.doi.org/10.1525/jer.2013.8.4.37

Copyright: University of California Press

http://www.ucpressjournals.com/

Postprint available at: Linköping University Electronic Press

http://urn.kb.se/resolve?urn=urn:nbn:se:liu:diva-102505 


\section{Brief Report: Ethical Problems in Research Practice}

Gunnel Colnerud

Linköping University, Sweden

\begin{abstract}
MOST ACCOUNTS OF THE ETHICAL problems facing researchers across a broad spectrum of research fields come from ethicists, ethics committees, and specialists committed to the study of ethics in human research. In contrast, this study reports on the ethical questions that researchers, themselves, report facing in their everyday practice. Fifty-five Swedish researchers contributed 109 examples of ethical dilemmas, conflicts, and problems in research. They were all researchers at the postdoctoral level in the fields of medicine, the humanities, education, and the social sciences, who devoted at least 50 percent of their working hours to research. They reported issues they face before, during, and after gathering data. Their range of issues is broader than generally discussed and points to the importance of researchers' ethical sensitivity.
\end{abstract}

KEY WORDS: research ethics, ethical problems in research; informed consent, risks of harm

Received: March 22, 2013; revised: August 26, 2013

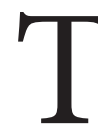
His ARTICLE PResents SELECTED FINDings from an extensive study of ethical problems that researchers actually face in their everyday practice Background, theoretical starting points, methods, and a more elaborated discussion of this study are found at [PE: Insert URL of online supplement here]. Fifty-five participants have contributed 109 examples of ethical dilemmas, conflicts, and problems in research. They were all researchers at the postdoctoral level in the fields of medicine, the humanities, education, and the social sciences, who devoted at least 50 percent of their working hours to research. The concerns are grouped as concerns perceived before data collection, during data collection, and after data collection.

\section{Findings}

The general classification principle for the cases which the researchers reported is based on that of Petersson (1994): before data collection, during data collection, and after data collection.

\author{
Before Data Collection
}

The questions that concern researchers before data collection mainly involve variations of problems relating to consent. However, the choice of scientific theme, research problem, or object for investigation can also raise ethical issues.

CHOICE OF RESEARCH PROBLEM

Questions concerning research ethics arise as early as the stage at which the theme or object to be researched is chosen. For example, a researcher who studies selfharming behavior points out the risk that the research itself may reinforce the harmful behavior. The research subjects receive attention and, up to a point, appreciation because they are, as a result of having self-harmed, the objects of the research. There is a risk that the research affirms the adolescents' identification of themselves as self-harmers, and thus worsens preexisting harm.

\section{INFORMATION FOR THE RESEARCH SUBJECT}

The comprehensive requirement to provide information to research subjects causes two types of problems for researchers. The first is that too much information can arouse unwarranted suspicion. Some researchers claim that fewer people consent when the information provided to them is detailed. The other problem involves the requirement that persons be told that participation is voluntary and that they have the right to withdraw, creating a risk of selection bias. For example, in questionnaire studies in school classes:

[T]here should not be any pressure, it should be completely voluntary ... you get pretty large groups of students who say, "No, I don't fancy answering that right now." We get a response rate which is about half that of comparable studies that we performed 15 years ago, when the regulations were a little bit different. We follow the recommendations from the ethics board; I think that it is obvious that this should be done. The consequences are that you end up with a dataset which is much worse, and it is the students who do not feel at home in school who refuse to take part, but it is their voices which really should be heard.

Journal of Empirical Research on Human Research Ethics, Vol. 8, No. 4, PP. 37-41. PRINT ISSN 1556-2646, ONLINE ISSN 1556-2654. (C) 2013 By JOAN SIEBER. ALL RIGHTS RESERVED. PLEASE DIRECT ALL REQUESTS FOR PERMISSIONS TO PHOTOCOPY OR REPRODUCE ARTICLE CONTENT THROUGH THE UNIVERSITY OF CALIFORNIA PRESS'S RIGHTS AND PERMISSIONS WEBSITE, HTTP://WWW.UCPRESSJOURNALS.COM/REPRINTINFO.ASP. DOI: $10.1525 /$ jer.2013.8.4.37 
The right to withdraw leads to problems with the quality of the data and to the risk that valuable data will be missed. Quality standards for methods, as a consequence, come into conflict with the standards of research ethics.

\section{CONSENT}

Problems relating to consent appear in many variants. The researchers demonstrate, through their accounts, that they respect the standard relating to informed consent, but sometimes quality is sacrificed as a result; however, in other cases, they are able to solve the problems without losing important data.

In certain studies, the requirement for consent is hard to determine or hard to implement. Studies carried out online raise such problems. The fact that people have voluntarily published their affairs online does not mean that they have agreed to take part in research. For example, a researcher who studies the cultural expression of grief said:

People who publish information online must be aware that others can look at it and that they do not have control over what other people do with it. But I, as a researcher, have a responsibility to my informants.

However, when researchers make contact in order to gain consent, they run the risk of "barging in on their extremely difficult situation."

In studies of discrimination in the labor market, methods are used which involve submitting fictitious job applications. Asking the employer being studied to consent will thwart the aim of the study. A researcher reported that the ethics review board disapproved such a study because confidence in research is at risk if researchers study people's actions without them being aware that they are taking part in research.

Studies of groups, such as classrooms of children, are thwarted when some of the potential research subjects who are invited to participate in research decline to consent. In classroom studies, vexing problems sometimes occur when all of the parents of the children in a class do not give their consent for their children's participation. In an observational study which involved video recording, one parent demanded total anonymity. The researcher solved the problem by dimming the recorded material. Another researcher, who filmed a classroom at a high school where one of the pupils had refused to take part, pointed the camera so that the specific student was not filmed. There was a problem when the pupil moved about in the classroom. A similar case is described in the following way:

[I]t can happen that there are pupils who do not want to take part. That's happened to me over the years, it is also a dilemma when you are going to film in a classroom ...We usually do it so that we point the camera in such a way that the children do not appear ... though now, there is often a lot of movement in the classroom which means that these children end up in the shot, in which case we usually erase them directly, so we take that out. I realize that a child may be living under a protected identity ... so I think it is important that they are not shown.

This researcher takes the problem seriously and does not exclude the possibility that there may be good reasons why a pupil does not wish to be filmed. The problem may be solved with the help of technology.

Another problem arises when a study is stopped because a parent says no, but the pupils had become enthusiastic about the possibility of taking part in the project. The researcher in this case indicated that it is "a little bit delicate withdrawing in such a way as to prevent there being repercussions for the child whose parents said no." She thinks there is a risk that the pupils' disappointment about the cancelled research project may be directed against the pupil whose parents caused the project to be cancelled.

Children and parents have, all too often, different attitudes toward taking part in a research project. In a classroom study which involved the recording of pupils' speech during lessons, all but one of the pupils' parents had consented to their children taking part. The researchers set up microphones on all but one of the pupils' desks. Not unexpectedly, this pupil would also like to take part in the project. She would also like to have a microphone on her desk. The researchers felt they were forced to comply with the parents' decision.

Adolescents who consent to take part in a study may sometimes fail to appear for the interview. This can be interpreted as a refusal to take part or it may simply be that they have forgotten. The researcher's problem is in deciding which of these is the case. If the subject does not wish to take part, but has trouble saying no directly to the researcher, it would be wrong to contact them to remind them about the agreement, according to the researcher.

In summary, researchers deal with a variety of problems related to informed consent. There may be a conflict between standards of method and standards 
of research ethics. This applies to, for example, methods for recruiting participants, easing the access to data, and concealing the ultimate aim of the research in order to be able to draw conclusions from the data. The requirements of the method are weighed against the standards of research ethics. In the examples that were provided by the research subjects in this study, research ethics carried more weight than the requirements of the method. The costs are, in certain cases, low, such as when removing a pupil from a recording. They are higher when it affects the voluntary nature of participation.

\section{During Data Collection}

In the contact between researchers and their subjects that occurs when data are collected, various problems and risks of an ethical nature may arise. The values which are at play are, above all, the risk of harming the research subjects physically or psychologically, or of violating their right to personal integrity and selfdetermination.

\section{THE RISK OF PSYCHOLOGICAL OR PHYSICAL HARM}

Researchers may risk harming the research subjects psychologically in interview studies into topics which are sensitive, shocking, or worrying. That a question is sensitive can sometimes come as a surprise to the researcher. It is, therefore, important to be prepared for unexpected things to happen.

One example of a study that is undoubtedly and predictably sensitive is an interview study with relatives of patients who have committed suicide. Despite careful preparation, the researcher only discovered during the interview that the man she was interviewing had not previously realized that his wife had killed herself. The interview subject, the husband, became shocked when he realized what had happened. The researcher took responsibility by arranging for the subject to receive help to process this shocking realization.

It is important to be prepared for unexpected and unpredictable situations, even within research areas that are not necessarily regarded as sensitive or shocking. One researcher discovered that even interviews about football can upset delicate feelings:

We interviewed a man who had been very involved in a football club; he was not a player, but a supporter of this particular club ... he broke down in tears and then it emerged that he had been ill and had received, while he was in hospital, a bunch of flowers from the club ... he became so emotional while he described this; this football club means so much to him, when he is in the hospital and is very much alone and then he gets this bunch of flowers ... it was an example of what can really happen when you least expect it.

Such surprises are not unusual. The risk increases when researchers find themselves in settings where they lack control over the conditions. For example, high school pupils constituted the research subjects in a project that dealt with climate change. The adolescents were involved in group discussions and several pupils asserted that the end of the world was near. A doomsday mood spread through the group; the researcher felt that the discussion had become too heavy and did not want the pupils to take this mood away with them. The researcher was placed in an ethical dilemma: to remain in the role of researcher and leave the pupils in that state or to leave that role and attempt to instill a little hope in the pupils. This researcher chose the latter and pointed out some solutions to the climate problem that are being worked out at a political level, in order to change the mood of despair to one of "a little more hope."

In a study of chemistry teaching, the researchers witnessed the pupils pouring poisonous material down the sink. The teacher had his attention focused in another direction. The researchers were surprised and could not bring themselves to intervene. This case concerns harm that could occur to third parties due to mercury poisoning of the environment we all share.

Classroom research brings privacy issues to the fore, particularly when it involves audio or video recording. Children may, for example, disclose sensitive personal information during an otherwise harmless study. Researchers who have been involved in video recordings describe how they edit out just such information from the film.

\section{MINIMIZING HARM}

A research project investigated whether patients had received information about the potential secondary effects of the treatment they were undergoing. The risk that this question would worry the patients seemed obvious. To send a questionnaire in which the research subjects are asked whether they have received information about possible side-effects demands careful consideration. "Is it ethical to send a letter or a questionnaire to people saying, 'Hi, you have been through this treatment, have you received information that there are potential side-effects'?" The researcher in question tested the project's information letter and questionnaire on several people in order to find a way to formulate it that minimized the risk of causing worry. 
Research involving children places particular demands on the researcher's awareness about the risks of causing harm. In one project, children's memory of unpleasant medical treatments was studied. The researchers showed the children objects from the treatments, e.g., an inhalation mask, and wanted to measure their pulse with a pulse oximeter, but the children reacted negatively to this. The researchers were disappointed since the study could not be conducted as planned. They chose a method that did not provide all the information they had hoped for, but which they viewed as ethically sound.

In summary, the knowledge sought by the researchers may call for methods that are moderately intrusive and therefore constitute a risk of causing harm, which stands in opposition to the standards of research ethics. The researchers described how they balance these different considerations by adapting their methods in order to minimize the risk of harm.

\section{After Data Collection}

The ethical problems that were reported after data collection, and before publication, concern authenticity, selection of quotes, cleaning up the language, and anonymizing for publication.

AUTHENTICITY-SELECTION OF DATA, CLEANING UP

THE LANGUAGE

When analyzing data, the researcher makes a judgment about whether specific data are relevant to the research question. One researcher describes having doubts about why all of the data are not reported. The screening of the information itself creates a feeling that "one is almost lying in some way."

Another fidelity problem concerns the transcription of speech, which almost always looks bad when written down. Respect for the research subjects stands in conflict with being faithful to the data.

\section{ANONYMITY OF DATA FOR PUBLICATION}

Protecting informants by rendering their statements and other data anonymous may involve problematic balancing acts. The researchers considered how many factors in a contextual description it is possible to report without there being a risk of disclosing participant identity. For example, should one publish the names of deceased persons who have been convicted of crimes? This can, for example, concern homosexual acts, which were previously illegal. While publication of names can be seen as an invasion of privacy, it may also provide redress to the forgotten. Rendering the data anonymous is one way of making it possible to discuss stigmatized behavior.

Researchers also reported requesting consent prior to the publication of quotes from the research participants whose position in the workplace may be at risk.

In summary, the researcher is faced with a deliberation, within the context of the writing process, about being faithful to the research subjects' actual contributions. Ethical standards may be incompatible with data integrity.

\section{Discussion}

The ethical problems in research which researchers have reported from their own practice are more varied than regulations and legislation appear to indicate. The researcher's ethical sensitivity, discretion, and judgment are thus a necessary guarantee of the ethical standards of the research.

The researchers in this study make few references to regulations or principles. One exception is when rules constitute such a great barrier that they threaten the scientific quality of the research-for example, when the selection becomes biased because the participants have been informed that participation is voluntary, and hence decide not to take part.

Furthermore, it may be noted that the kinds of events researchers describe tend to be everyday events in the lives of researchers, not the rare and dramatic kinds of events reported in some papers on research ethics. We should be pleased with the ethical sensitivity of the researchers. It has been questioned whether research within the social sciences actually involves significant risk of causing harm (Capron, 1983). There is not, perhaps, a risk of serious harm. However, researchers fortunately also attempt to avoid these less serious risks. The self-policing, to which Dingwall (2012) referred, seems to have survived thus far. Moreover, it may be noted that ethics wins out over other standards when ethical consideration comes into conflict with scientific quality.

\section{Research Agenda}

The method for this study has its shortcomings. The researchers describe situations which they solved with careful consideration given to the standards of research ethics in order to protect the research subjects. Other descriptions, such as those where the research ethics had fallen short, must be investigated with other methods. 


\section{Acknowledgment}

I am grateful to the Swedish Research Council for funding this research.

\section{Author Note}

Please address correspondence to Gunnel Colnerud, Department of Behavioral Research and Learning,
Linköping University, S-581 83 Linkoping, Sweden. e-mail: gunnel.colnerud@liu.se.

\section{Author's Biographical Sketch}

Gunnel Colnerud is Professor of Behavioral Research and Learning at Linköping University. Her main research interests are professional ethics, especially in the fields of research, teaching, and psychology.

\section{References}

Capron, A. M. (1983). Prospects for research ethics. In K. Berg \& K. E. Tranøy (Eds.), Research ethics. New York:Alan R. Liss. Dingwall, R. (2012) How did we ever get into this mess?

The rise of ethical regulation in the social sciences. Studies in Qualitative Methodology, 12, 3-26.
Petersson, B. (1994). Forskning och etiska koder. [Research and ethical codes.] Nora, Sweden: Nya Doxa. 